\title{
Patterns of information flow in local cortical networks
}

\author{
Sunny Nigam", Olaf Sporns², Masanori Shimono', John M Beggs \\ From The Twenty Third Annual Computational Neuroscience Meeting: CNS*2014 \\ Québec City, Canada. 26-31 July 2014
}

Structural and functional connectivity of macroscopic brain regions has been very widely researched [1] in the last decade, however very little work has been done on the effective connectivity between individual neurons, largely because of limitations on the simultaneous measurement of large numbers of neurons at high spatiotemporal resolution. We recorded spontaneous single neuron activity from 15 organotypic cultures (prepared from the mouse cortex), with a 512 channel micro-electrode array at a temporal resolution of less than $1 \mathrm{~ms}$ and a spatial resolution of $60 \mu \mathrm{m}$. The average number of recorded neurons was $347 \pm 119$. Effective connectivity matrices, both binary and weighted, were constructed from the spike trains using transfer entropy (TE) analysis to estimate directed neuronal interactions [2]. The strength of information flow from neuron $i$ to $j$ was quantified in terms of the TE value calculated from neuron $i$ to $j$. We observed that only $20 \%$ of the recorded neurons accounted for $80 \%$ of the total information flow in these networks (see Figure 1A) which we define as the network's set of rich nodes. The rich nodes were characterized by a higher firing rate, and graph theoretic analysis revealed their participation in a number of highly non-random network features. The networks were highly clustered with small average path
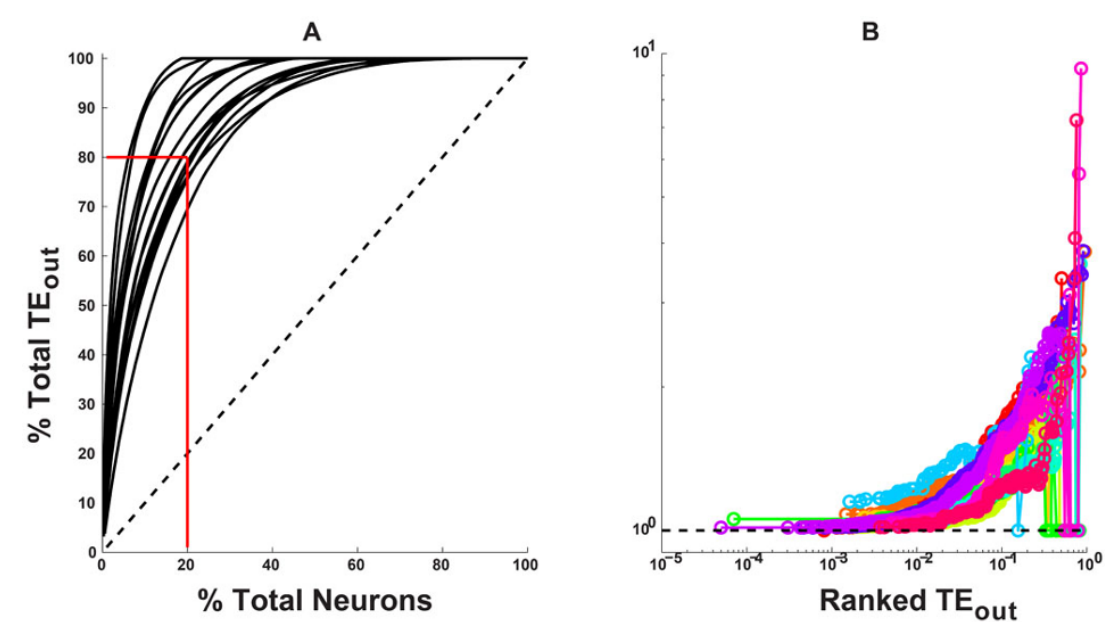

Figure 1 A) Cumulative distribution of total-outgoing TE (solid black lines) as a function of the percent of contributing neurons. Dotted black line shows what the distribution should have been for a network with uniform distribution of information flow. B) Normalized weighted rich club coefficient plotted versus the ranked richness parameter ( $\left.T E_{\text {out }}\right)$. A coefficient greater than 1 for a range of values of the ranked richness parameter implies the existence of a rich club in the network

* Correspondence: nigams@indiana.edu

'Department of Physics, Indiana University, Bloomington, IN 47405, USA

Full list of author information is available at the end of the article Attribution License (http://creativecommons.org/licenses/by/4.0), which permits unrestricted use, distribution, and reproduction in any medium, provided the original work is properly cited. The Creative Commons Public Domain Dedication waiver (http:// creativecommons.org/publicdomain/zero/1.0/) applies to the data made available in this article, unless otherwise stated. 
lengths and thus exhibited small world attributes and the sub-network formed by the rich nodes was more efficient than the rest of the network. The networks also exhibited a central core of rich nodes which persisted even when the rest of the nodes in the network were peeled away. The rich nodes were also connected to each other more strongly than expected by chance giving rise to the rich $c l u b$ effect, observed for the first time in effective connectivity networks of individual neurons (see Figure 1B). The rich club effect has previously been shown to exist in the structural connectivity between macroscopic brain regions in cat, macaque monkey and humans [3] and between neurons in C. Elegans [4].Our findings suggest that networks of TE effective connectivity in mouse cortex contain a subset of highly connected and highly interactive neurons reminiscent of rich club organization observed at larger scales.

\section{Authors' details}

'Department of Physics, Indiana University, Bloomington, IN 47405, USA. ${ }^{2}$ Department of Psychological and Brain Sciences, Indiana University,

Bloomington, IN 47405, USA.

Published: 21 July 2014

\section{References}

1. Bullmore E, Sporns O: Complex brain networks: graph theoretical analysis of structural and functional systems. Nat. Rev., Neurosci 2010, 10:186-198.

2. Schreiber T: Measuring information transfer. Phys Rev Lett 2000, 85:461-464.

3. van den Heuvel MP, Sporns O: Rich club organization of the human connectome. J. Neurosci 2011, 31:15775-15786.

4. Towlson EK, Ve'rtes PE, Ahnert SE, Schafer WR, Bullmore ET: The rich club of the C. elegans neuronal connectome. J Neurosci 2013, 33:6380-6387.

doi:10.1186/1471-2202-15-S1-P213

Cite this article as: Nigam et al:: Patterns of information flow in local cortical networks. BMC Neuroscience 2014 15(Suppl 1):P213.

\section{Submit your next manuscript to BioMed Central} and take full advantage of:

- Convenient online submission

- Thorough peer review

- No space constraints or color figure charges

- Immediate publication on acceptance

- Inclusion in PubMed, CAS, Scopus and Google Scholar

- Research which is freely available for redistribution

Submit your manuscript at www.biomedcentral.com/submit 